\title{
REAL TIME SHIPMENT TRACKING SYSTEM USING RFID
}

\author{
MEDHAT H. A AWADALLA
}

College of Engineering, Electrical and Computer Engineering Department, SQU, Oman

College of Engineering, Communications, Electronics, and Computer Department, Helwan University,

\section{Abstract}

Egypt

This paper presents a viable system for online shipment tracking using RFID technology. It aims to find the location where exactly it is at an instance of time, from the time of shipment to the time of delivery. The system has a developed web-based database-driven application that facilities its management and provides useful information about the shipment. A complete prototype of the proposed system was implemented and tested to validate the system functionality. The results show that the system is promising for on line shipment tracking.

\section{Indexing terms/Keywords:}

RFID, Shipment tracking, Concept Fan and Analytical Hierarchy, web-based database-driven application.

\section{Subject Classification:}

Computer Engineering

\section{Type (Method/Approach):}

Analysis/design/implementation/tesing

\section{Introduction}

Online shopping nowadays is huge due to free trade and globalization. In 2014, United Parcel Service (UPS) shipping company [1] delivered about 4.6 billion packages. People and companies need to trace their packages to know when they will be arrived and where they are now. Due to huge competitions, many companies pay a lot of money to provide new and better services. Companies try to develop remarkable systems to be used by the customers and themselves to efficiently manage packages and track them.

Different approaches have been used for this purpose; the most commonly used one is the barcode technology. It is cheap and simple to use, however it is easy to damage and if it is damaged, it will be unrecognizable [2-3]. A QR code is almost as the bar code, and it the ability to carry much data than the barcode, however it is slow to scan the data.

Radio Frequency Identification (RFID) technology that helps a lot in accelerating processes and completing tasks in time. Nowadays, RFID technology is commonly used almost everywhere and it is still expanding more and more due to the continuous drop in its price and the continuous improvements in its functionality. It provides better solutions for many of today's problems [4-7]. RFID system contains three components: Transponder (tag/smart label) including data memory and antenna, Read/write unit (reader) with antenna and Processing Software [8-10].

To trace a package, a checkpoint is a place where packages arrive to register its status, arrival time and send a feedback about its status and new location. After that, it is either forwarded to the next checkpoint or kept there to deliver it to the receiver. Most of companies use this method to track packages, because of its simplicity and reliability. At any checkpoint, a computer is connected to RFID tag reading device. The RFID reader then reads the tag and starts sending the package's information to a computer connected to the system.

- $\quad$ After the package is registered in the system, the package will pass through several checkpoints.

- $\quad$ As the package reaches a checkpoint, that checkpoint will be considered as the package's last location.

- That checkpoint' computer communicate with the server.

- $\quad$ The new data (including the status and location) will be sent to the server.

- $\quad$ The database will be updated with the new data.

The rest of the paper is organized as follows. Section 2 presents the system specification. It includes marketing and engineering requirements and mapping table to show the relationship between engineering and marketing requirements. The design of the system is presented in the section 3. An analytical hierarchy process (AHP) 
and the concept fan are illustrated in section 4 . Section 5 gives the developed database and the website. Section 6 illustrates the developed system tests. Section 7 concludes the paper.

\section{The proposed system overview}

In shipping management system, there is usually a process to ship a package/parcel from sender to receiver. Figures 1 and 2 show the block diagram and the system overview to carry out the shipment management system. After receiving the package from the sender, the first thing to do is registering the package. In registration stage, the details of the package are stored in a database. The carriers will access database in order to deliver the package by giving them access to the database. At each checkpoint, package's information will be updated in the database. In addition, it will be updated when the package is delivered to the receiver. Figures 3-5 show the flowcharts from the point of view of customer, company, and the carrier to depict the details of on line shipment tracking system.

$\begin{array}{ll}\text { Nomenclatures } \\ \text { C } & \text { Criterion } \\ \text { CF-RU5106 } & \text { RFID Type } \\ \text { EPC C1G2 } & \text { RFID Active TAG } \\ \text { MD5 } & \text { 120-bit Hash Function } \\ n & \text { Number of data set }\end{array}$

Greek Symbols

$\begin{array}{ll}- & \text { No relation } \\ \uparrow & \text { Positive correlation } \\ \downarrow & \text { Negative correlation } \\ \square & \text { Multiplication } \\ \square & \text { Increasing the desirability } \\ \square & \text { Decreasing the desirability }\end{array}$

\section{Abbreviations}

$\begin{array}{ll}\text { AHP } & \text { Analytical Hierarchy Process } \\ \text { CARR_ID } & \text { Carrier identity } \\ \text { CUS_ID } & \text { Customer Identity } \\ \text { CUS-FNAME } & \text { Customer First Name } \\ \text { CUS-LNAME } & \text { Customer Last Name } \\ \text { EMP_LNAM } & \text { Employee last name } \\ \text { E } & \\ \text { EMP_PASS } & \text { Employee password } \\ \text { WORD } & \\ \text { ER } & \text { Entity Relationship } \\ \text { EXPEC_- } & \text { Expected Delivery Date } \\ \text { DELV_- } & \\ \text { DATE } & \end{array}$




\begin{tabular}{|ll|} 
GM & Geometric Mean \\
ID & Global Positioning System (GPS) \\
IMP_ID & Identity \\
PACK__ & Employee Identity \\
Cost & Package Cost \\
PACK_ID & Package Identity \\
PHP & Personal Home Page \\
QR & Quick Response \\
RFID & Radio Frequency Identification \\
SQL & Structured Query Language \\
UPS & United Parcel Service \\
XAMPP & Cross-Platform (X), Apache (A), MariaDB (M), PHP \\
CHECKP_ID & Checkpoint identity \\
\hline
\end{tabular}



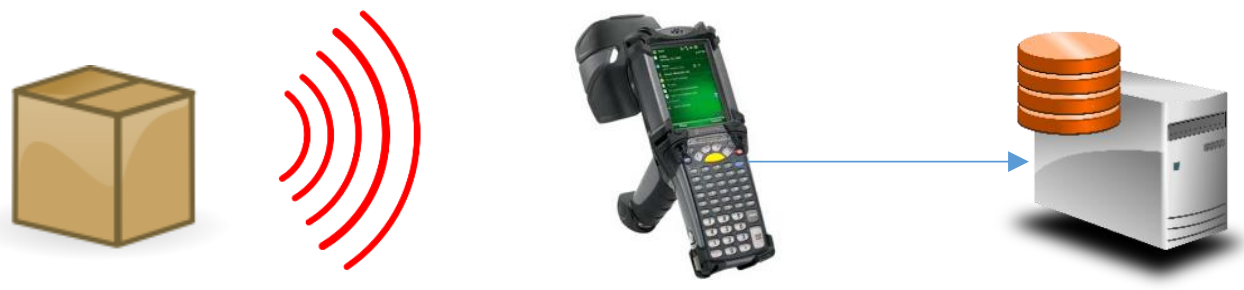

Fig. 1. The developed system block diagram

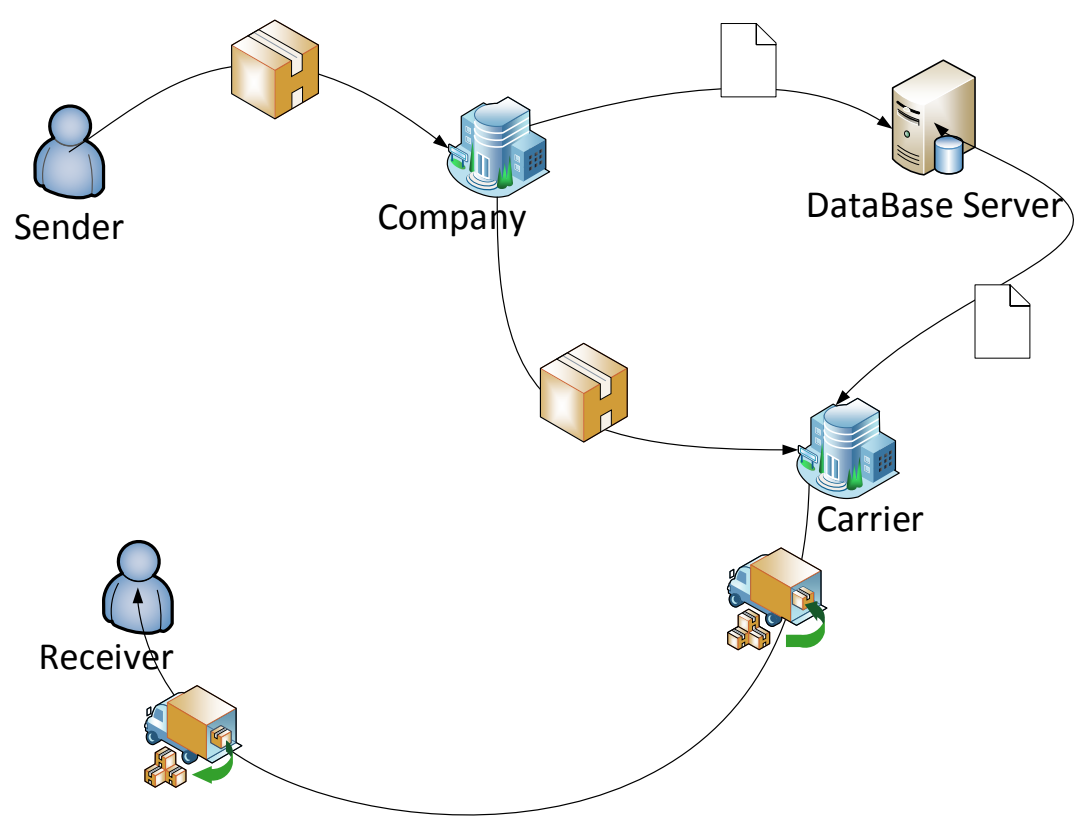

Fig. 2. The Developed system overview

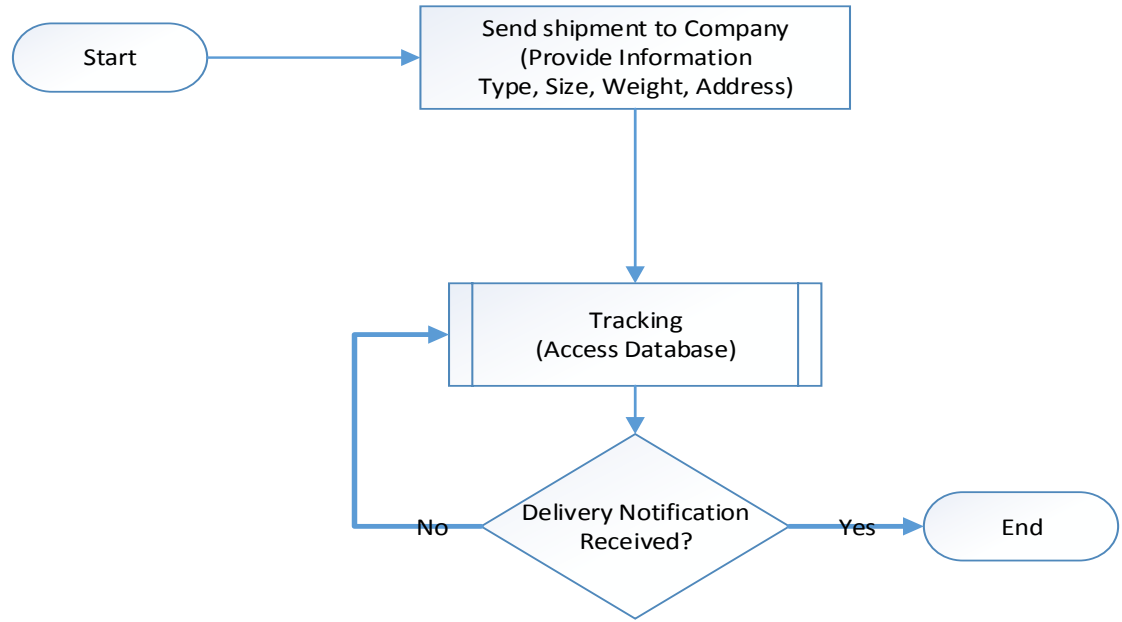

Fig. 3. The flowchart of customer point of view 


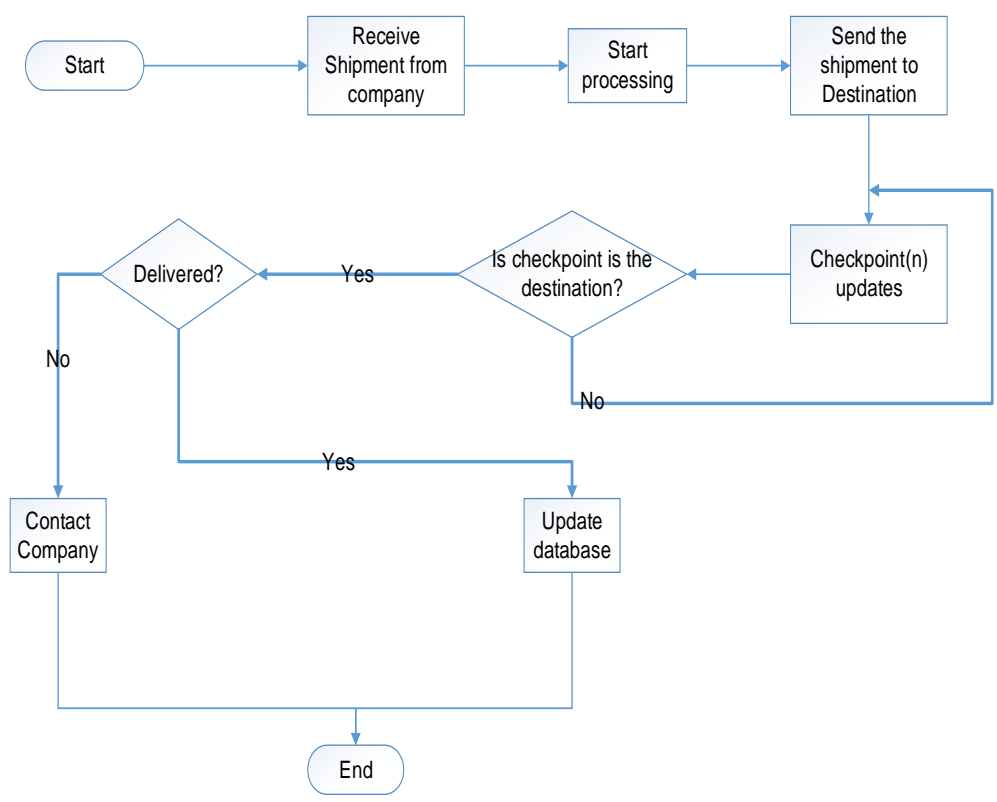

Fig. 4. The flowchart of company point of view

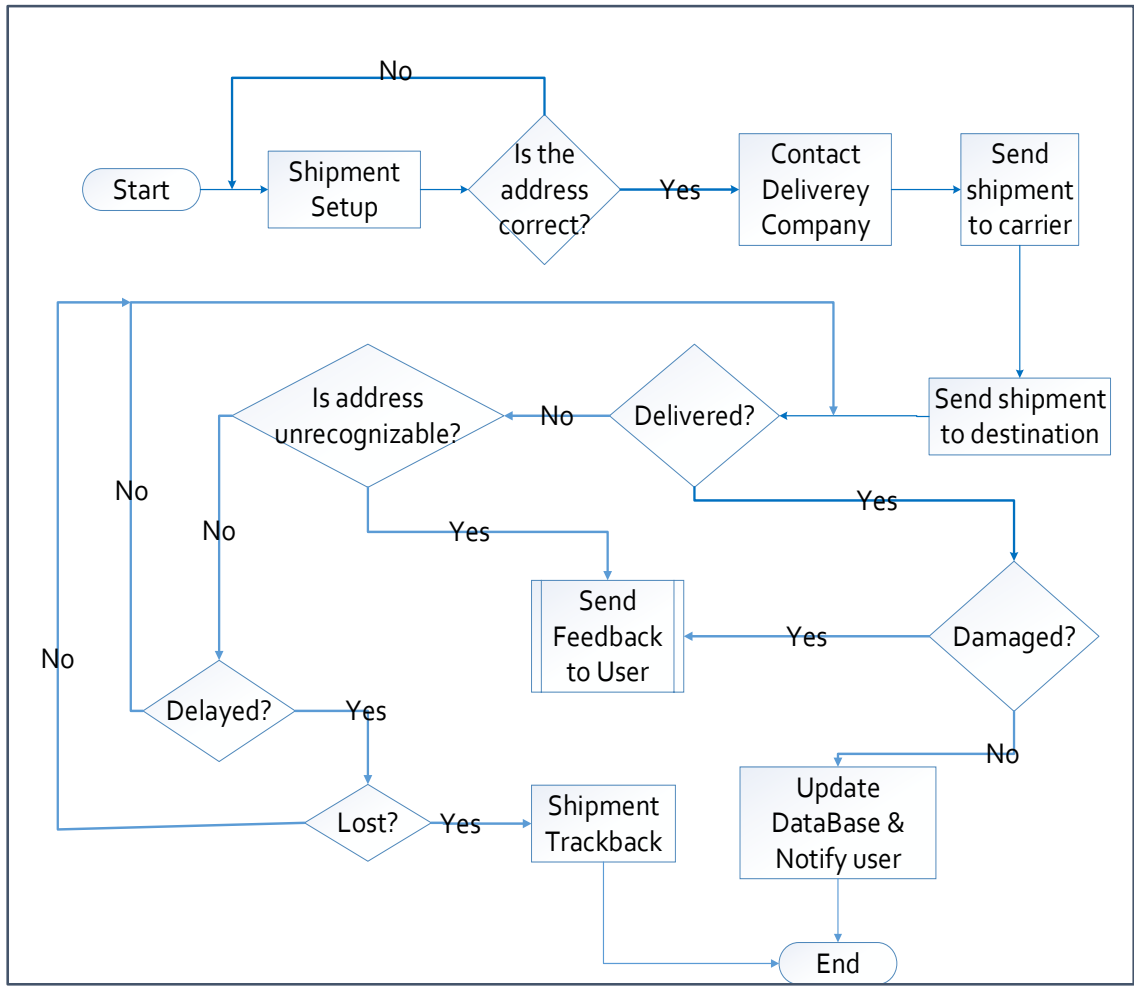

Fig. 5. The flowchart of carrier point of view 


\section{The system specification and synthesis}

The system requirements can be classified as marketing requirements and Engineering requirements. The marketing requirements explain the features the customer needs from the proposed system. For example, the system should be accurate, easy to use, have a fast response, durable, secure. However, the requirements of engineering point of view are to translate the marketing requirements into technical requirements. These technical requirements are the system should contain a simple interface, able to access the database easily and promptly, have another alternative plan to keep the system functioning, be easy to maintain, use an authentication to access the implemented database, be reliable and be able to trace at certain checkpoint along route. Table 1 illustrates the comparison between the marketing and engineering requirements. It uses symbols to depict the affection of each requirement of the others. A positive correlation ( $\uparrow$ ) means that both goals, the marking and Engineering requirements can be obtained, but negative correlation $(\downarrow)$ means that both goals cannot be obtained. The symbol (-) means that the marketing and engineering requirements have no relation. Positive + and negative - symbols to indicate increasing or decreasing based on the desirability of the each requirement.

Table 1. Engineering-Marketing Matrix

\begin{tabular}{|c|c|c|c|c|c|c|c|}
\hline \multirow{2}{*}{\multicolumn{2}{|c|}{ Marketing Requirements }} & 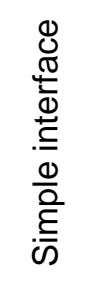 & $\begin{array}{l}\frac{}{0} \\
\frac{\pi}{0} \\
\frac{0}{2} \\
\frac{v}{0} \\
\mathbb{D}\end{array}$ & 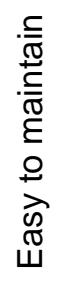 & 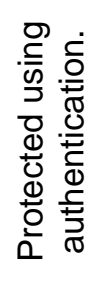 & 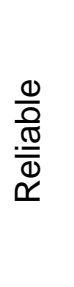 & 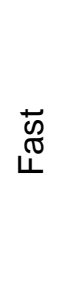 \\
\hline & & + & + & + & + & + & + \\
\hline Accurate information & + & - & - & - & - & $\uparrow$ & $\downarrow$ \\
\hline Easy to use & + & $\uparrow$ & - & $\uparrow$ & - & - & $\uparrow$ \\
\hline Fast response & + & $\uparrow$ & - & - & $\downarrow$ & - & $\uparrow$ \\
\hline Durable system & + & - & $\uparrow$ & $\uparrow \uparrow$ & - & $\uparrow$ & - \\
\hline Secure system & + & $\uparrow$ & - & $\uparrow$ & $\uparrow$ & $\uparrow$ & $\downarrow$ \\
\hline Tracking & + & - & $\uparrow$ & - & - & - & $\downarrow$ \\
\hline \multicolumn{2}{|l|}{$\begin{array}{l}\text { Targets for engineering } \\
\text { requirements }\end{array}$} & $\begin{array}{l}\text { PHP } \\
\text { format }\end{array}$ & Daily & - & $\begin{array}{c}\text { MD5 } \\
\text { hashin } \\
\mathrm{g}\end{array}$ & SQL & RFID \\
\hline
\end{tabular}

The packages to be identified and recognized, there are different techniques that can be used such as barcode, Quick Response (QR) Code, and Radio Frequency Identification (RFID). The disadvantages of barcode technique as mentioned earlier are their short ranges, impossible to read many packages at the same time, and it cannot read if it is damaged by get dirty. The advantages of QR are low cost and simple in use. In the other hand, it takes long time to scan the packages compared to RFID and barcode [11]. Since the packages can travel long distances based on the destination and it becomes more difficult to trace, this unit is critical part. Two approaches can be used to trace the packages:

- Global Positioning System (GPS).

- Checkpoint marking.

GPS is more accurate in terms of location. In the other hand, it has higher cost than using checkpoint marking. GPS required a new device to be installed in order to work. Checkpoint marking has the advantage of less cost and reliability [12-14].

\subsection{Concept Fan and Analytical Hierarchy Process (AHP)}

The graphical demonstration of different available design alternatives is called concept fan. As shown in Fig. 6, it is used to show different possible components and technologies as alternatives to choose among them to construct the required system. 


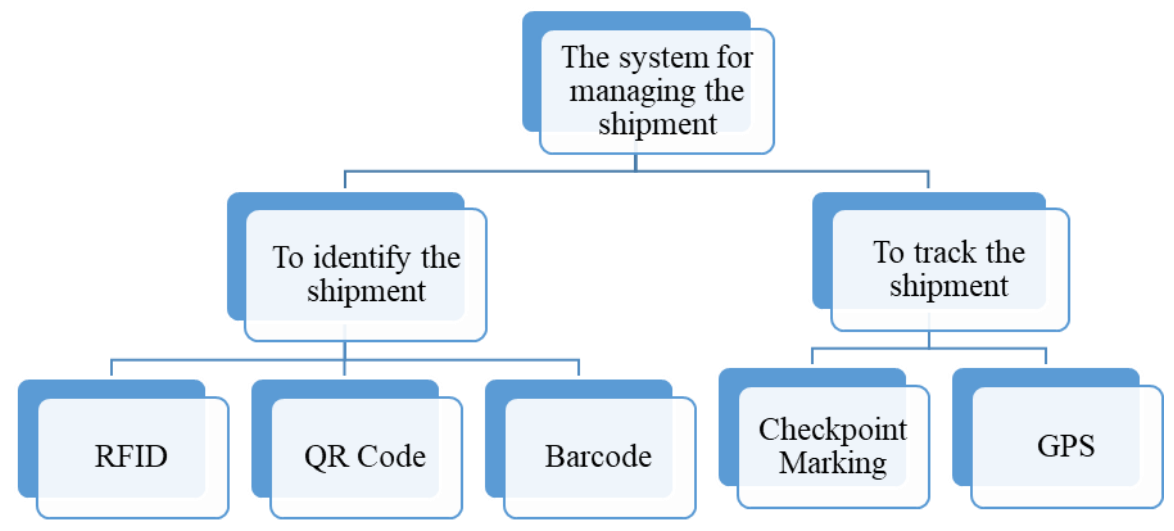

Fig. 6. The shipment tracking system concept fan

AHP is defined as a technical methodology that can be used to compare different alternatives to choose the remarkable one of them. In this paper, different parameters have been addressed and AHP is performed to find the best applicable approach/component. The used criteria are the cost of the system, the response of the system in terms of seed, how to reuse the system, reusability, and the maximum range that can used [15]. The geometric mean for data set $\{a 1, a 2, \ldots$, an $\}$ and the weight for each criterion $\mathrm{Ci}$ are calculated based on the following formula 1 and 2 .

$G M=\left(\prod_{i=1}^{n} a_{i}\right)^{\frac{1}{n}}=\sqrt[n]{a_{1} a_{2} \cdots a_{n}}$.

(1)

$\operatorname{WEIGHT}\left(C_{1}\right)=\frac{G M\left(C_{1}\right)}{\sum_{i=1}^{n} G M\left(C_{i}\right)}$.

(2)

Table 2 depicts the pairwise comparison among different criteria. The comparison has been accomplished to find the value of the weights of each criterion. The key values are determined based on the relation between the technologies/components. For example, the key value 3 is three times important compared with the key value 1.

Table 2. Pairwise comparison of criteria selection to identify the shipment

\begin{tabular}{|c|c|c|c|c|c|c|}
\hline & Cost & Speed & Reusability & Range & GM & Weights \\
\hline The cost & 1 & 3 & 5 & $1 / 5$ & 1.3 & 0.276 \\
\hline The speed & $1 / 3$ & 1 & 7 & 3 & 1.6 & 0.34 \\
\hline The reusability & $1 / 5$ & $1 / 7$ & 1 & $1 / 3$ & 0.31 & 0.066 \\
\hline The range & 5 & $1 / 3$ & 3 & 1 & 1.5 & 0.318 \\
\hline Total & & & & & 4.71 & 1 \\
\hline
\end{tabular}

Table 3. Shipment Identification Matrix

\begin{tabular}{lcccc}
\hline & Achieved Weights & Barcode & QR code & RFID \\
\hline The cost & 0.276 & 0.39 & 0.4 & 0.22 \\
\cline { 2 - 5 } The speed & 0.34 & 0.28 & 0.19 & 0.56 \\
\cline { 2 - 5 } The reusability & 0.066 & 0.13 & 0.134 & 0.72 \\
\cline { 2 - 5 } The range & 0.318 & 0.3 & 0.131 & 0.65 \\
\cline { 2 - 5 } & The Score & 0.30682 & 0.225 & 0.505 \\
\cline { 3 - 5 }
\end{tabular}


Table 3 shows the shipment identification matrix where RFID has the highest score, 0.505; therefore, it is the most remarkable choice to identify the shipment. Table 4 illustrates the comparison conducted to get weights for the same criteria used for shipment tracking. Table 5 illustrates the comparison conducted to get weights for the same criteria used for shipment tracking. Table 4 shows the shipment-tracking matrix, Checkpoint Marking criterion has the higher score than GPS; therefore, it is most remarkable choice Checkpoint Marking for shipment tracking.

\section{The developed system database and website}

This section presents details about the developed database used, its specification, and ER model, the used software programs to implement them. The database and the website are the main parts of the system for customers to trace their packages in an efficient way.

Table 4. Pairwise comparison of criteria selection to track the shipment

\begin{tabular}{|c|c|c|c|c|c|c|}
\hline & $\begin{array}{l}\bar{\oplus} \\
\text { O }\end{array}$ & 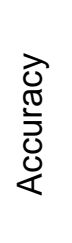 & 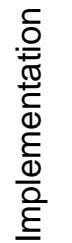 & 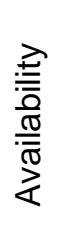 & $\sum_{\mathbb{N}}$ & $\begin{array}{l}\frac{n}{ \pm} \\
\frac{0}{0} \\
\frac{0}{3}\end{array}$ \\
\hline Cost & 1 & $1 / 5$ & 5 & 5 & 1.5 & 0.264 \\
\hline Accuracy & 5 & 1 & 3 & 7 & 3.20 & 0.563 \\
\hline Implementation & $1 / 5$ & $1 / 3$ & 1 & 3 & 0.668 & $\begin{array}{l}0.117 \\
6\end{array}$ \\
\hline Availability & $1 / 5$ & $1 / 7$ & $1 / 3$ & 1 & 0.31 & 0.054 \\
\hline Total & & & & & 5.678 & 1 \\
\hline
\end{tabular}

Table 5. Package Tracking Alternatives Matrix

\begin{tabular}{lccc}
\hline & Achieved Weights & GPS & $\begin{array}{c}\text { Checkpoint } \\
\text { Marking }\end{array}$ \\
\hline Purchase cost & 0.264 & 0.41 & 0.61 \\
Accuracy & 0.563 & 0.43 & 0.59 \\
Implementation & 0.1176 & 0.57 & 0.54 \\
Availability & 0.054 & 0.58 & 0.50 \\
Score & & 0.448 & 0.583
\end{tabular}

\subsection{Database}

The vital data related to the packages such as the package number, the sender name and its address, and the destination address should be addressed in a very proper. The most proper way is to store them in database. In this paper, Structured Query Language (SQL) is used to manage the database, SQL is a programming language interacting with the data to get information, modify it or even update it. In addition, XAMPP is used to construct the database. XAMPP is shown in Fig. 7, which is an offline tool to enable us to use Apache and to run MySQL. By running MySQL, there is built-in software called phpMyAdmin as an interface to make it easy to deal with the database being created. Further, it has many documentations and tutorials. It can create, edit and manage a database. phpMyAdmin is shown in Fig. 8. 


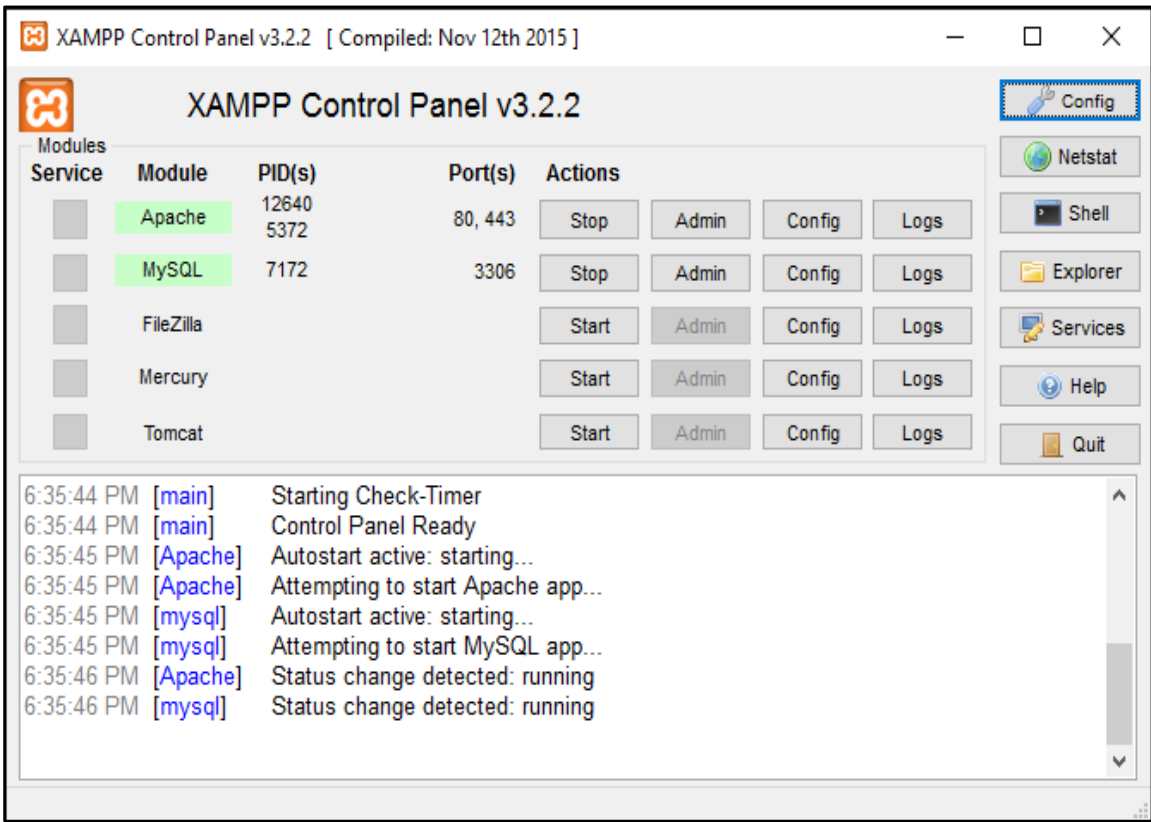

Fig. 7. The conducted Xampp software

\begin{tabular}{|c|c|c|c|c|c|c|c|c|}
\hline \multicolumn{7}{|c|}{ XAMPP Control Panel v3.2.2 [Compiled: Nov 12th 2015] } & - & $\square$ \\
\hline$\theta$ & \multicolumn{7}{|c|}{ XAMPP Control Panel v3.2.2 } & Config \\
\hline $\begin{array}{l}\text { Modules } \\
\text { Service }\end{array}$ & Module & PID(s) & Port(s) & Actions & & & & (1) Netstat \\
\hline & Apache & $\begin{array}{l}12640 \\
5372\end{array}$ & 80,443 & Stop & Admin & Config & Logs & 믄ll \\
\hline & MySQL & 7172 & 3306 & Stop & Admin & Config & Logs & Explorer \\
\hline & FileZilla & & & Start & Admin & Config & Logs & Services \\
\hline & Mercury & & & Start & Admin & Config & Logs & (3) Help \\
\hline & Tomcat & & & Start & Admin & Config & Logs & Quit \\
\hline \multicolumn{2}{|c|}{$\begin{array}{l}\text { 6:35:44 PM [main] } \\
\text { 6:35:44 PM [main] } \\
\text { 6:35:45 PM [Apache] } \\
\text { 6:35:45 PM [Apache] } \\
\text { 6:35:45 PM [mysql] } \\
\text { 6:35:45 PM [mysql] } \\
\text { 6:35:46 PM [Apache] } \\
\text { 6:35:46 PM [mysql] }\end{array}$} & \multicolumn{6}{|c|}{$\begin{array}{l}\text { Starting Check-Timer } \\
\text { Control Panel Ready } \\
\text { Autostart active: starting... } \\
\text { Attempting to start Apache app... } \\
\text { Autostart active: starting... } \\
\text { Attempting to start MySQL app... } \\
\text { Status change detected: running } \\
\text { Status change detected: running }\end{array}$} & $\wedge$ \\
\hline
\end{tabular}

Fig. 8. The developed phpMyAdmin interface

\subsubsection{Database specification}

The first step to design a database is to write the full specification. A package has a unique ID (RFID Tag), sender information, receiver information, weight, dimension, description, status, date of shipping and arrival date. The package has a status like damaged, lost, in transit, delivered, delayed, sent to carrier or received from carrier.

The package itself belongs to one customer. The package will pass through different checkpoints. Each branch of the company is basically a checkpoint. In each checkpoint, the package status and location will be updated and forwarded to next checkpoint. The company is using different carriers. Each package has one carrier at a time. The carrier can access the information and update package's checkpoint and status. Customer and carrier both can have more than one package.

The shipping company consists of managers, employees, checkpoints and warehouses. Each employee is working in one checkpoint at a time. If that employee is moved to another checkpoint, his information will be 
part of the new checkpoint. Employees are responsible for registering packages. In addition, employees are able to access and change information about the package. In addition, an employee will access the system using his/her username and password through a website. Furthermore, employees will register carriers to give them access to some functions in the database. The company will contact carriers to provide them the information about the packages. Each carrier has a username and password to access a database. The carrier can provide the expected delivery time and the cost of shipping.

Every package reaches a warehouse of a checkpoint should be immediately registered in the system or its status should be updated. Shipping company will make a list of carriers and their prices according to shipping type and weight. The company will add its profit according to the expenses.

The second step is to extract the nouns and verbs. Each noun is considered as separate entity and each verb is a relation between those entities. In database, each entity is a table and each table has columns to describe attributes of that entity and rows to describe data. Each row is called a record, which is a set of data as shown in Fig. 9

\subsubsection{ER-Diagram}

ER-Diagram is necessary to understand the relations between entities. As shown in the Fig. 9, there are seven entities: Customer, Package, Carrier, Employee, Payment, Location, and Checkpoint. Each entity has a primary key which is a unique id used to identify each record. Inside entity, there is a group of attributes. The attributes are the required fields to be filled with data about each record. For example, Customer entity has a record about one of the customers. This customer will have a primary key (CUS_ID), a first and last name (CUS-FNAME, CUS-LNAME), address, phone and email. Each entity has relations with other entities. There are different types of relations such as one-to-one, one-to-many and many-to-many.

This ER diagram was implemented using phpMyAdmin. The database was created. In order to access this database, php code is used to implement it.

\subsection{The Developed Website}

A website has been developed in this paper to help customers to trace their packages by entering the ID number of the package to know its last status. In addition, they can get benefits from other services available on the that website to use, for example checking the allowed goods to be shipped, prices and many other services. The website was designed using html, php and few of java scripts programming languages. Fig. 10 is showing the developed web page for tracking shipments. 


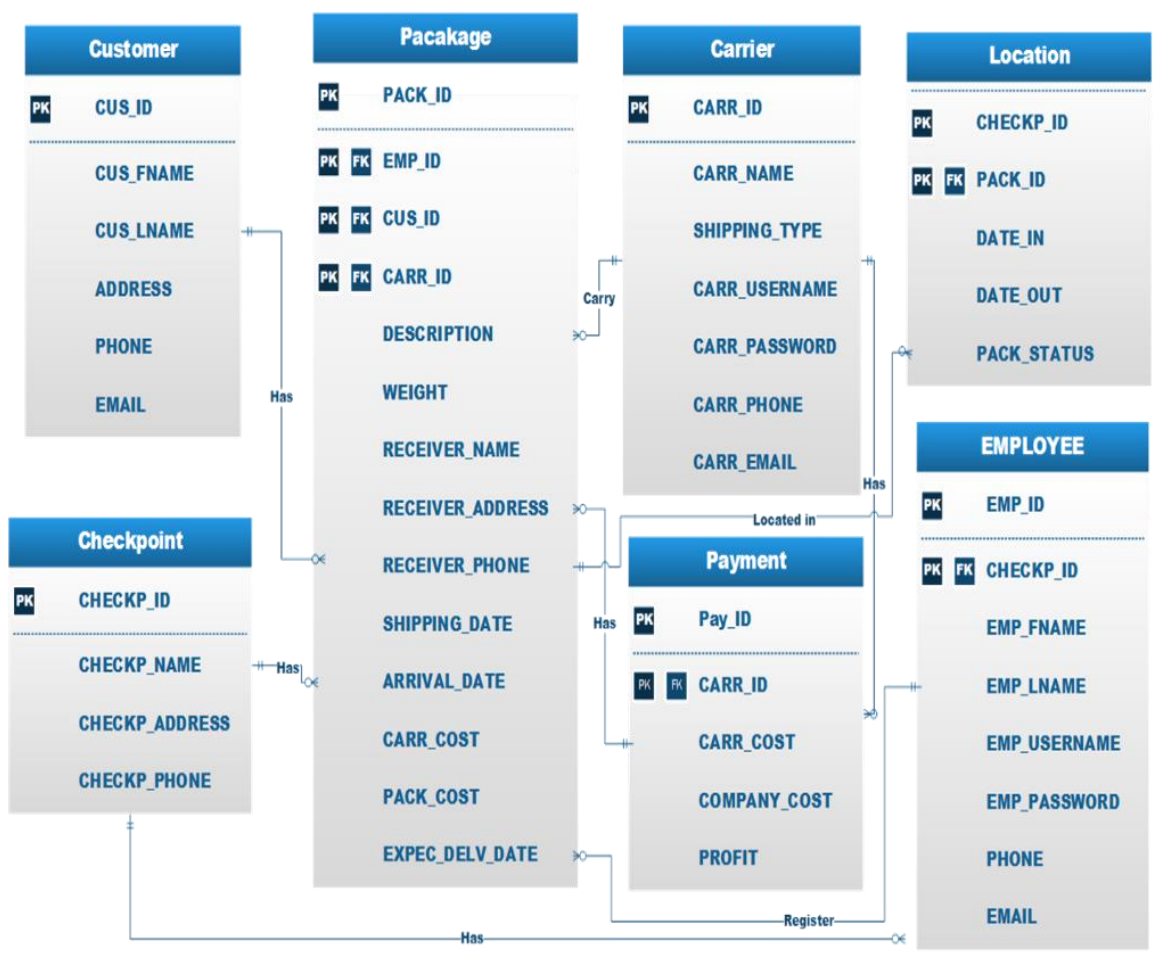

Fig. 9. The developed ER diagram

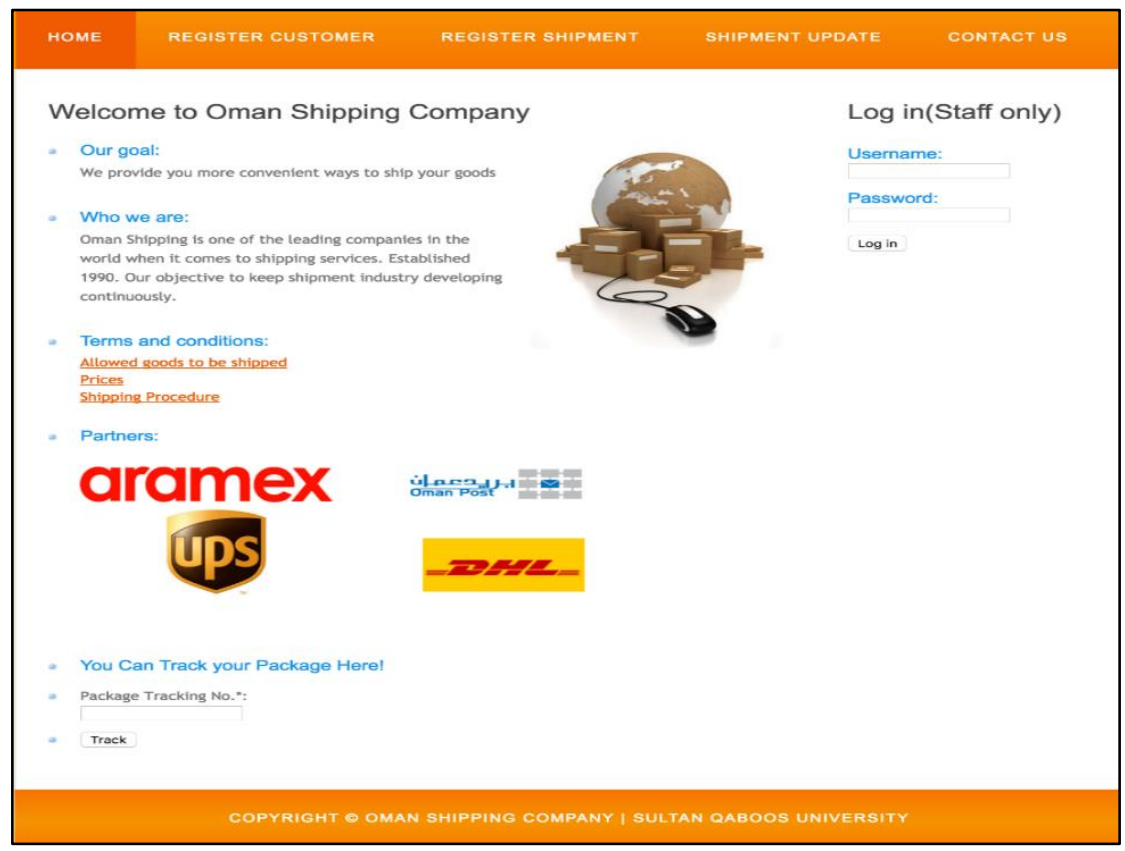

Fig. 10. Main page of the Website

\section{IMPLEMENTATION AND TESTING}

To verify and validate the desired function of the developed system, a model for the system is implemented and tested. The function of RFID technology is investigated first to check if it reads the package information stored in the tags successfully or not. CF-RU5106 RFID with active tags of type EPC C1G2 is chosen and set as illustrated in Fig. 11. Number of different tags have been read correctly as shown in Fig. 12. Both of shipping company and carrier employees are supposed to access the database, so they will have user names and passwords. The password is encrypted using MD5 hashing [17] to make it secure. An administrator, to give them access to the database, should register each of those employees. When they try to get access, their 
passwords are converted to hash values using hashing function. Hash values will be compared to the hash values stored in the database. If they are matched, they will be given access. Employees now can use their access to register new customers or packages or update their information. The carrier now can update some of the information of packages. For example, the carrier can update expected delivery date and the cost. Different scenarios for shipment registration, shipment tracking, checkpoint update, and the shipment status are shown in Figures 13-21 have been conducted to test the performance of the whole system.

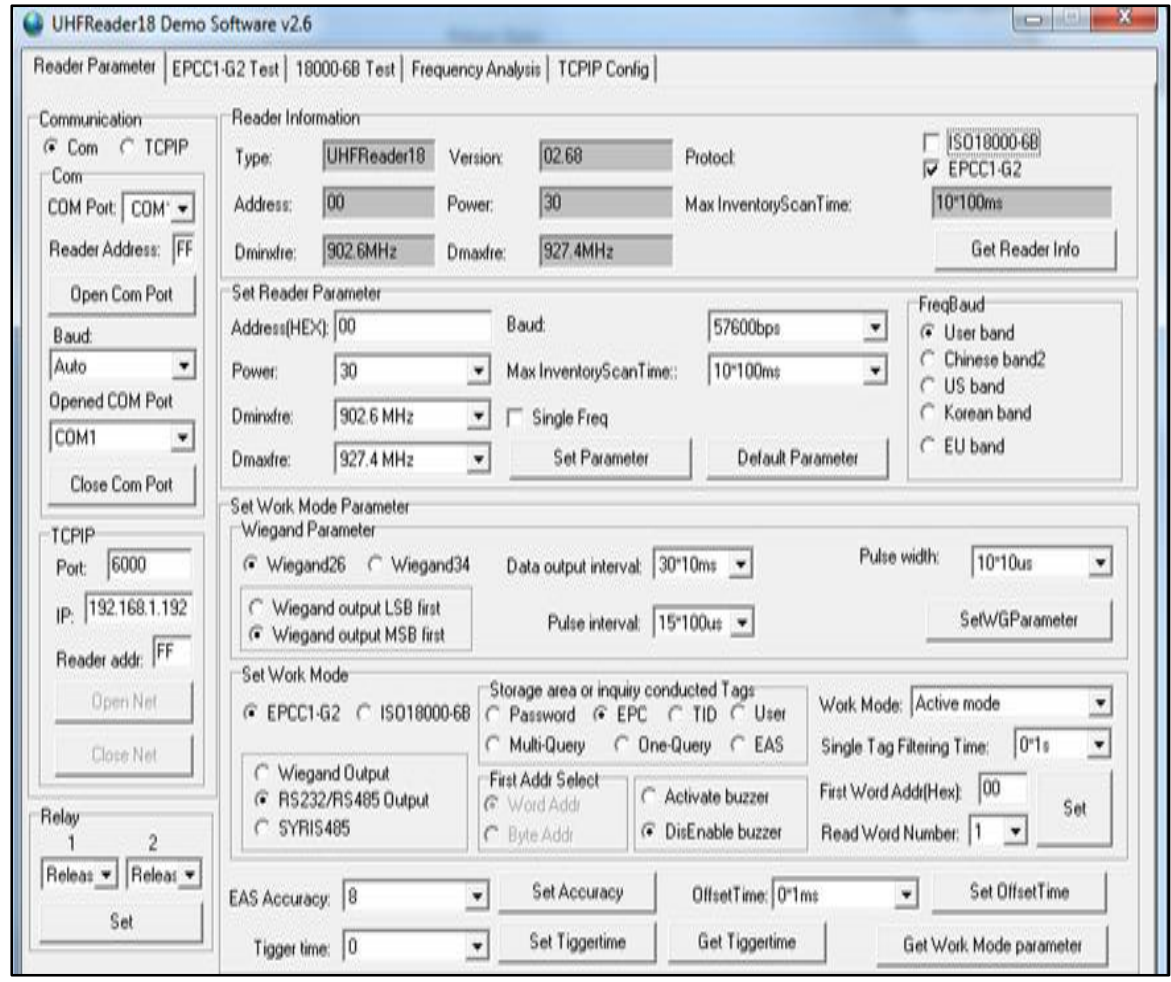

Fig. 11. RFID Reader Configuration

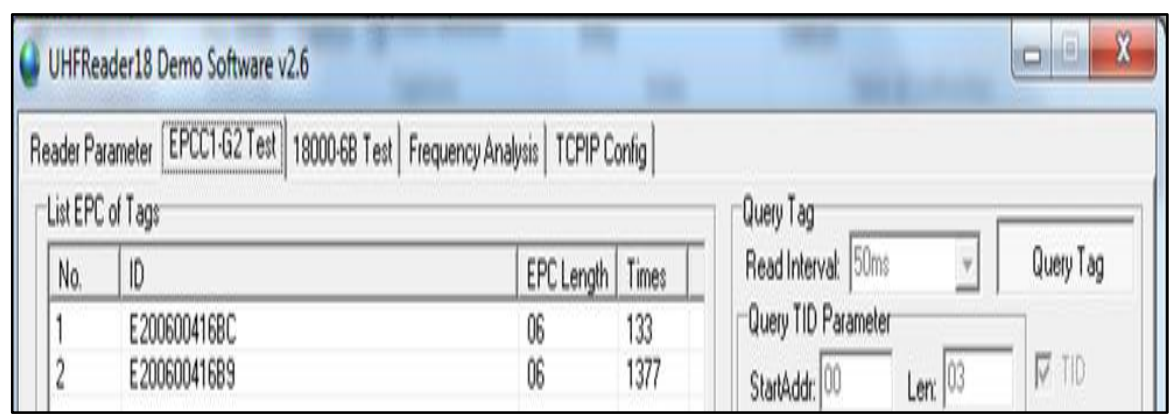

Fig. 12. Tags have been read successfully 


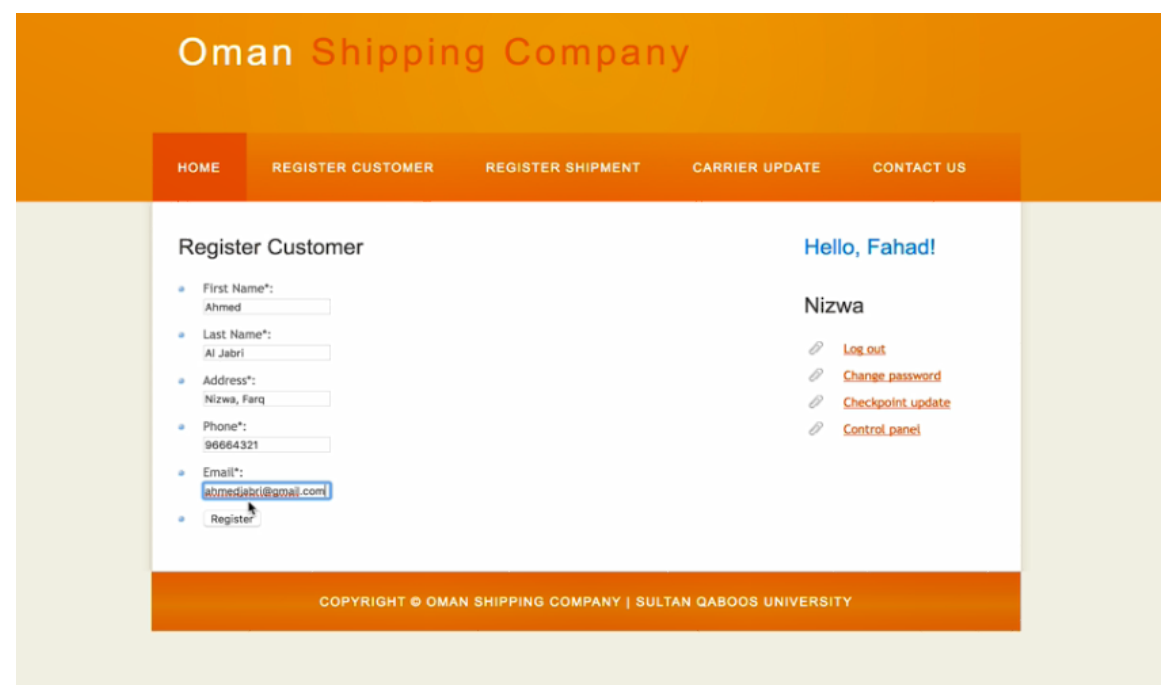

Fig. 13. Registering a new customer

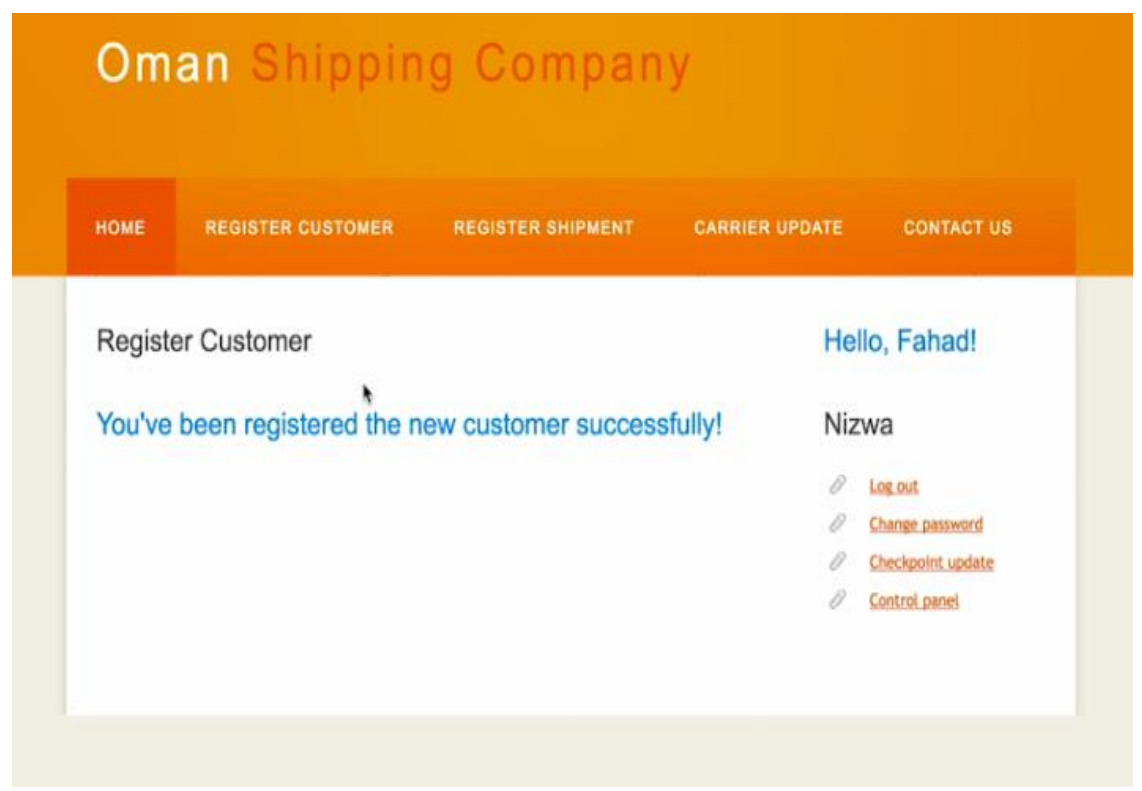

Fig. 14. A new customer is successfully registered 


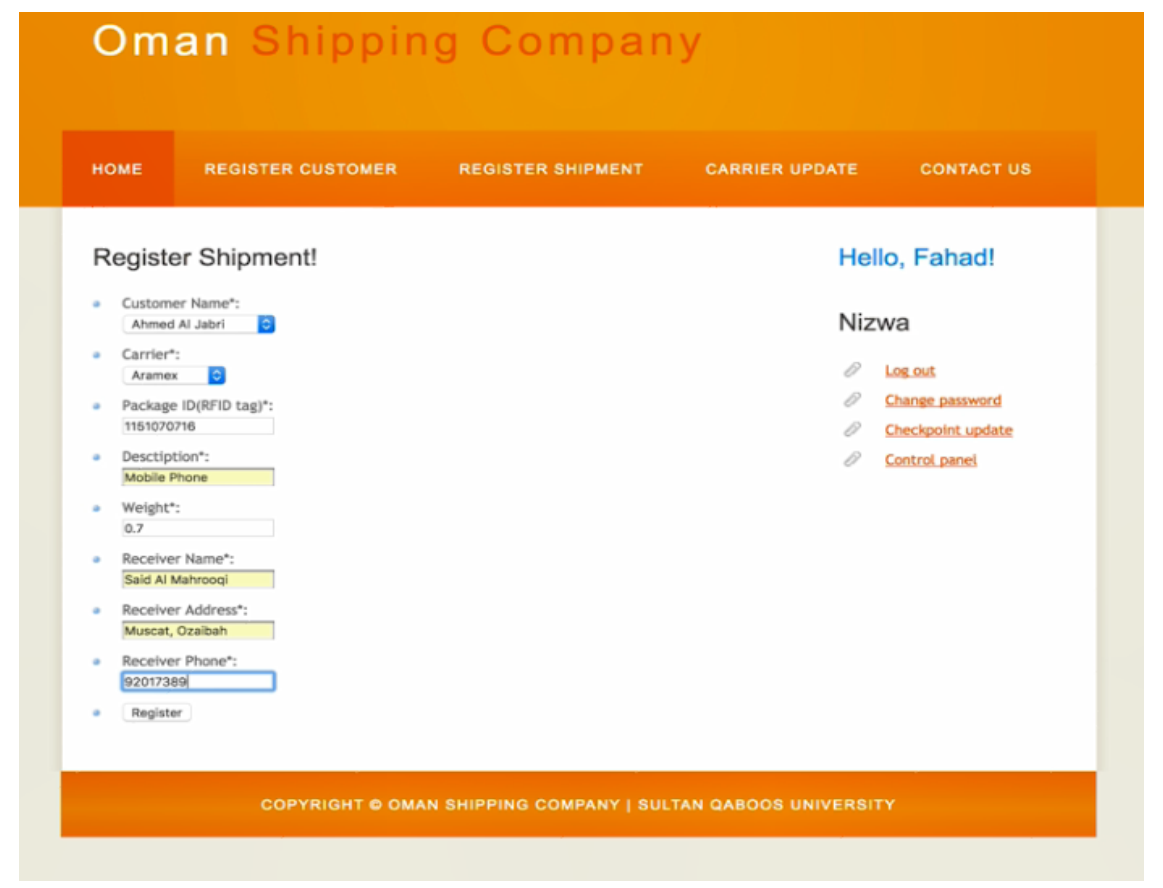

Fig. 15. The registration of a new shipment

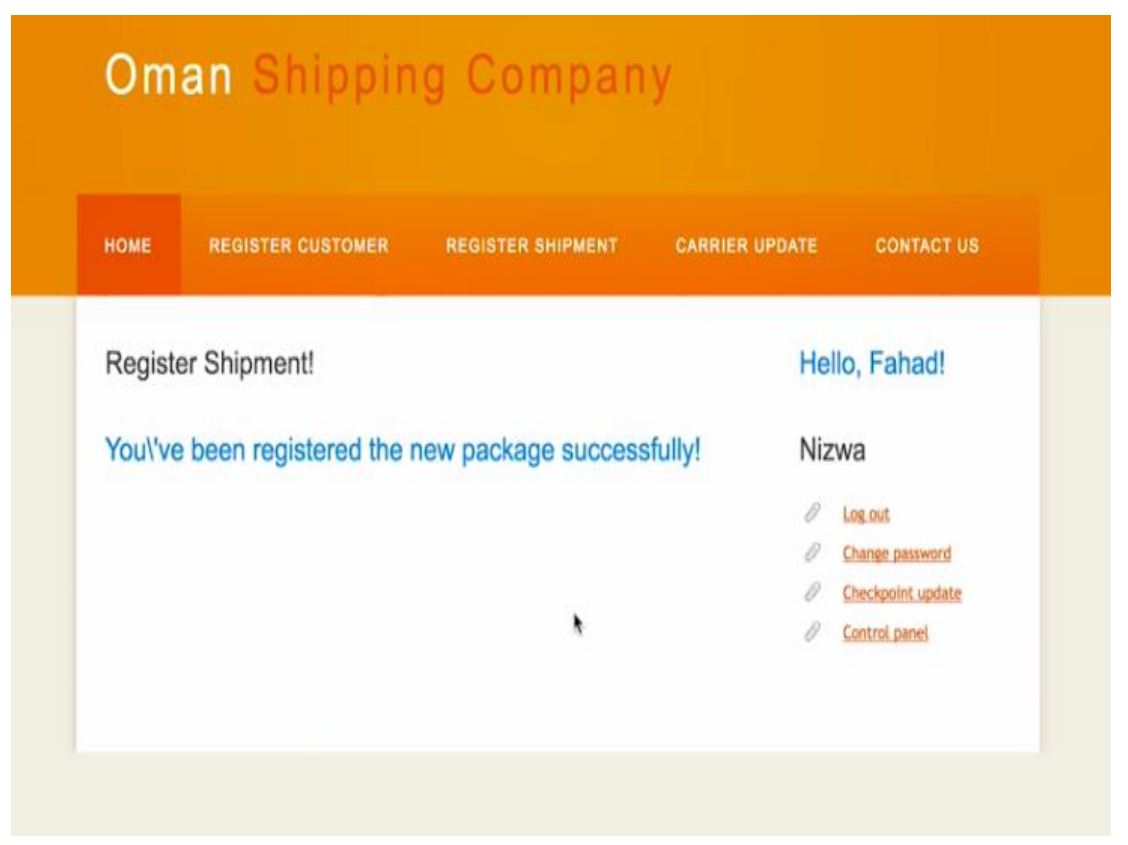

Fig. 16. A new shipment is successfully registered 


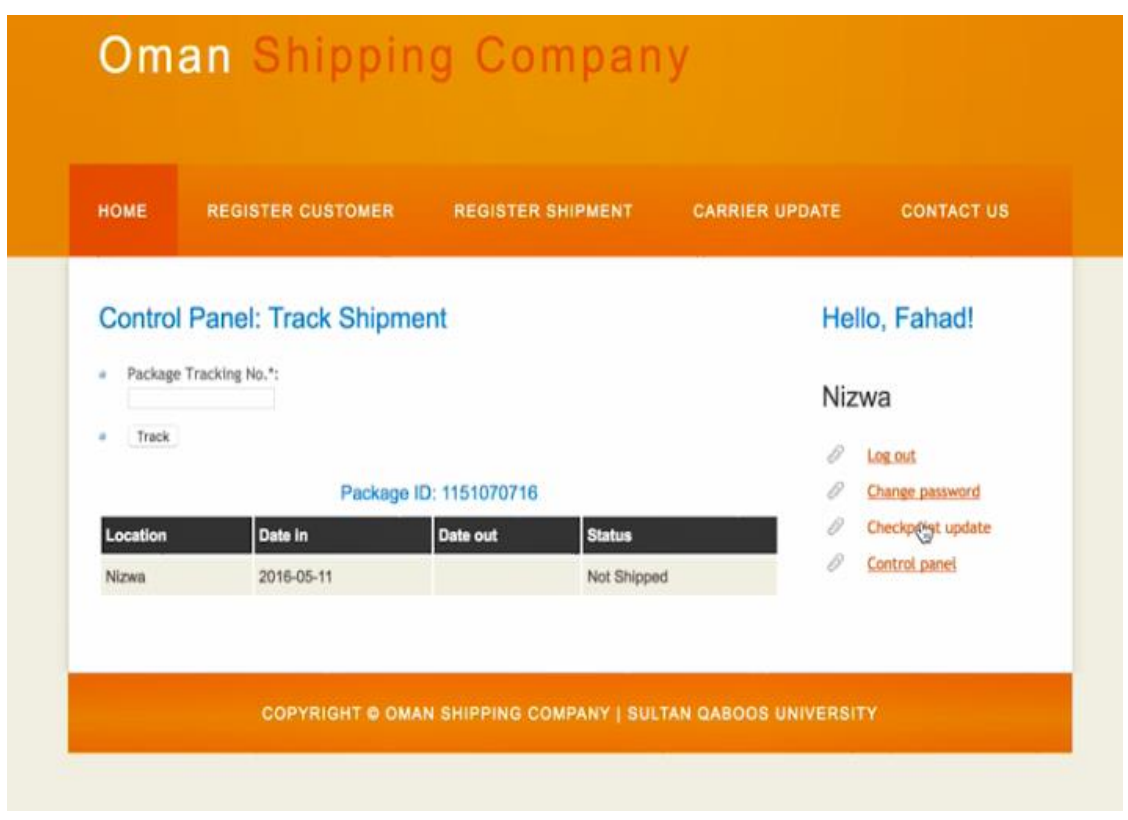

Fig. 17. Shipment tracking

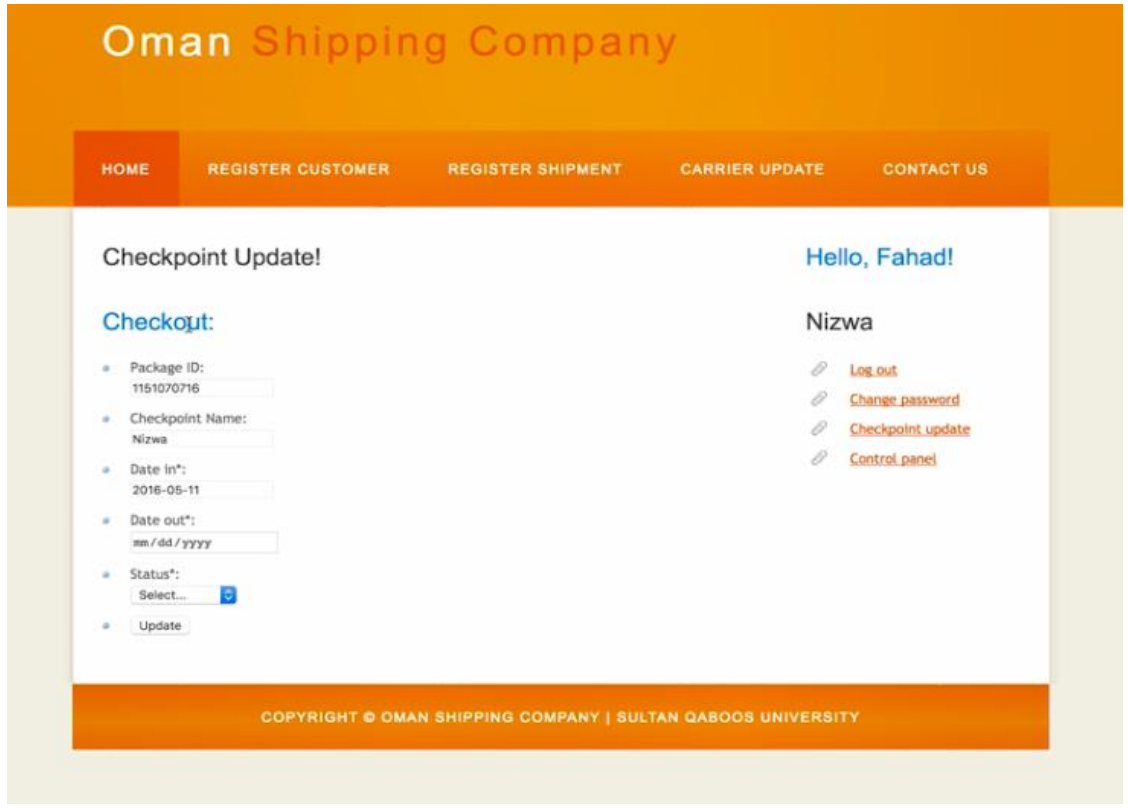

Fig. 18. Checkpoint is being updated 


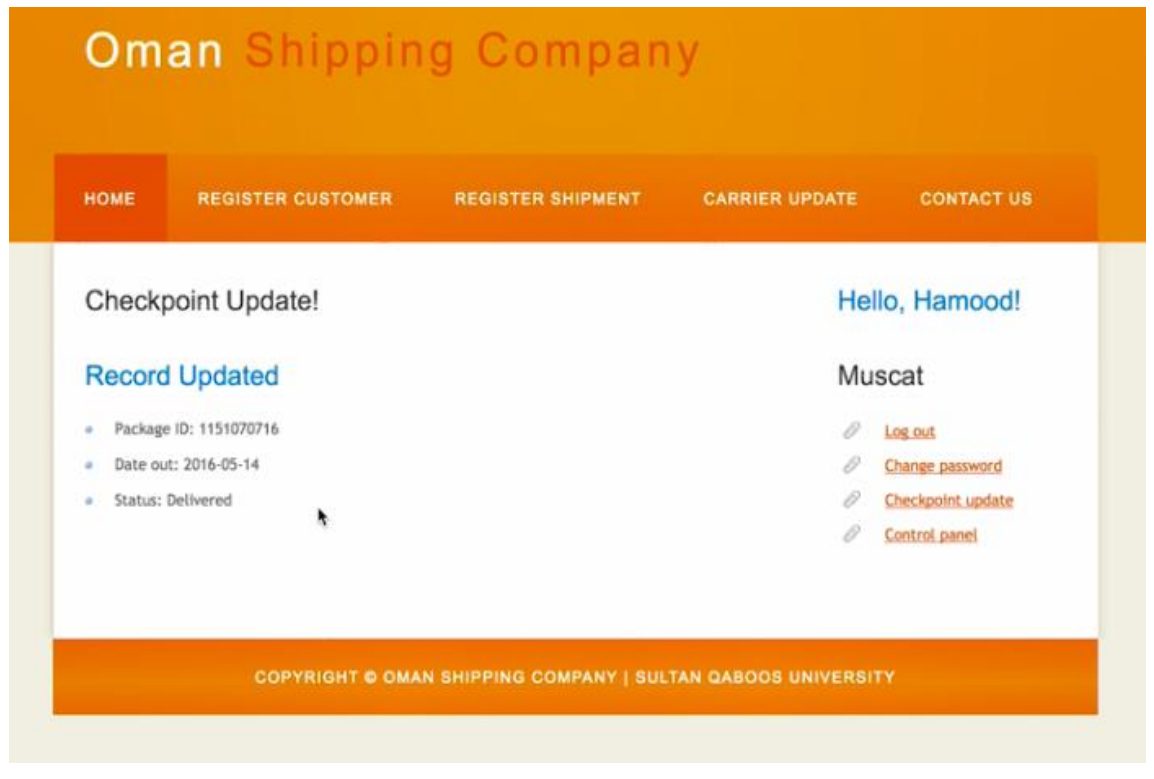

Fig. 19. Checkpoint is updated successfully

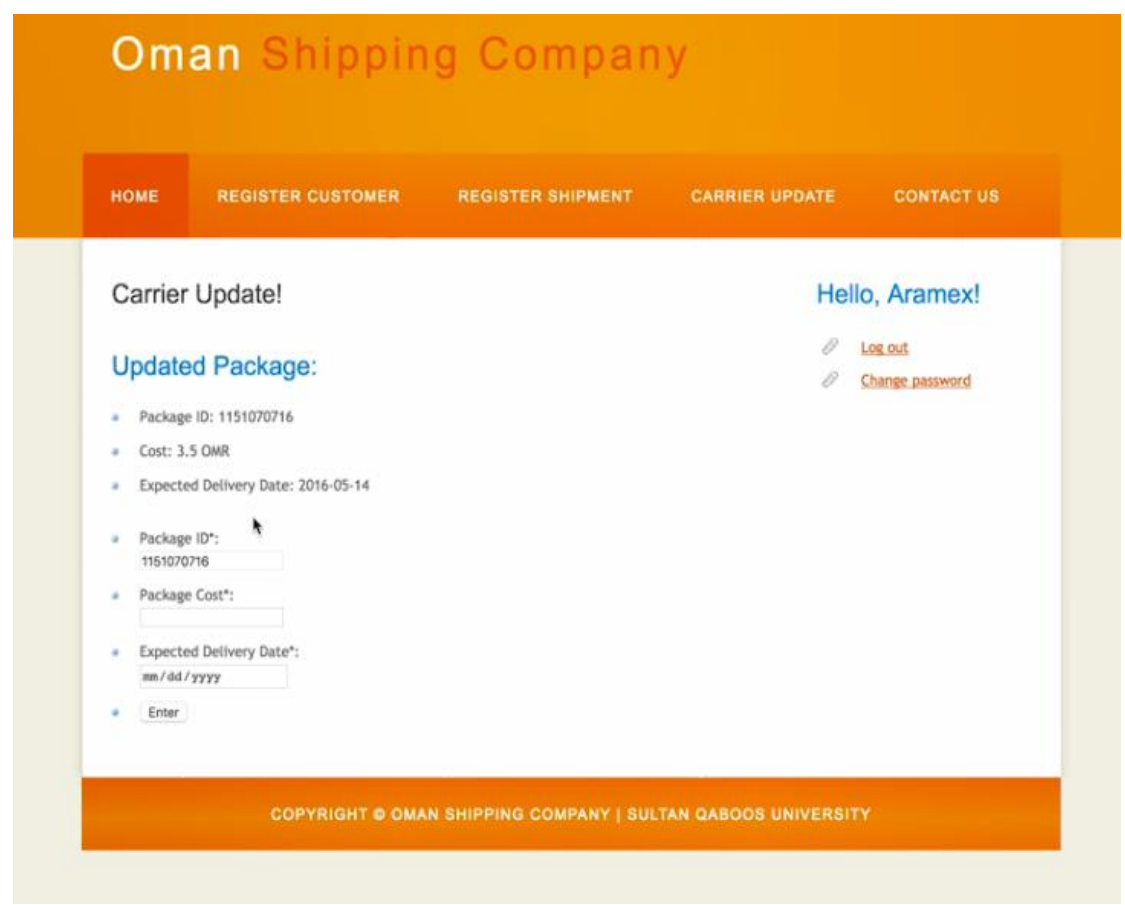

Fig. 20. Carrier Update 


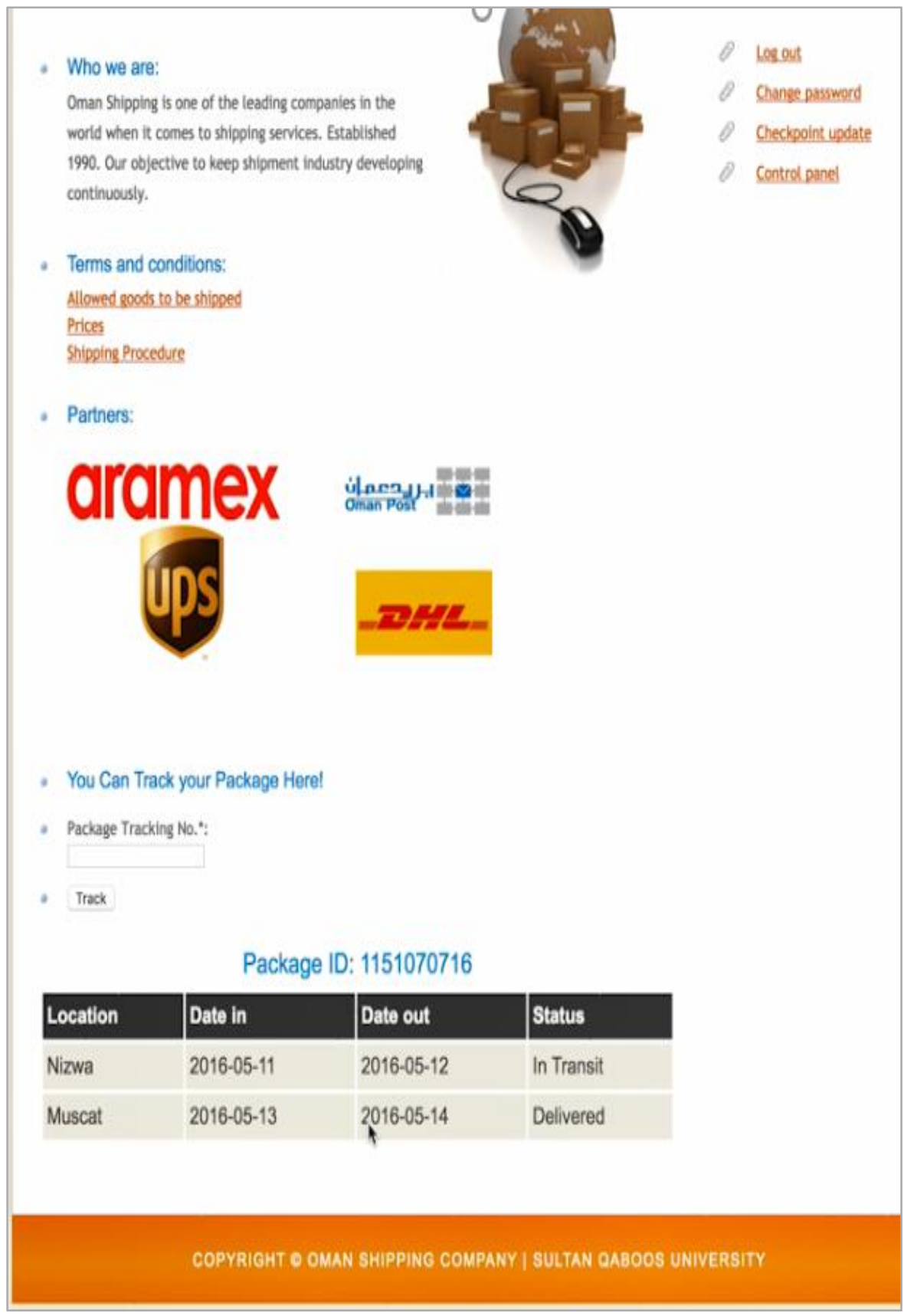

Fig. 21. The final status of the shipment

\section{Conclusion}

In this paper, an on line complete system for tracking packages using RFID technology has been designed. The developed system comprises database, website, and a user-friendly interface to follow the packages, knowing the status of the packages of being damaged or lost and its location until reaching its proper destination. The complete system has been tested for verifications, and achieved results were promising.

\section{References}

1. United Parcel Service of America, Inc. 2014. UPS: Worldwide. Retrieved 14 April, 2017, from https://www.ups.com/content/us/en/about/facts/worldwide.html.

2. Statista. (2014). United States: number of digital shoppers 2010-2018. Retrieved May 10, 2017, from http://www.statista.com/statistics/183755/number-of-us-internet-shoppers.

3. Bonsor, K.; and Fenlon, W. (2015). How RFID Works. Retrieved June 10, 2017, from http://electronics.howstuffworks.com/gadgets/high-tech-gadgets/rfid.htm. 
4. Delen, D.; Sharda R.; and Hardgrave, B. (2011). The promise of RFID-based sensors in the perishables supply chain. Wireless Communication, IEEE, 18(2), 82-88.

5. Al-Lawati, A.; Al-Jahdhami S.; Al-Belushi A.; Al-Adawi D.; Awadalla, M.; and Al-Abri, D. (2015). RFID-based System for School Children Transportation Safety Enhancement. Eighth IEEE GCC Conference and Exhibition, Muscat, Oman, 7-12.

6. Vidyasagar, K.; Balaji, G.; and Narendra, K. (2015). RFID-GSM imparted School children Security System. Communications on Applied Electronics (CAE) - ISSN: 2394-4714, 2(2), 17-21.

7. Malliga, R.; and Narmatha, T. (2016). RFID-based System for School Children Transportation Safety Enhancement. International Journal of Advanced Research in Computer Science and Software Engineering, 6(4), 2409-2415.

8. Yuan-Tsung, C.; and Timothy, K. (2017). RFID-Based intelligent parking management system with indoor positioning and dynamic tracking. 10th International Conference on Ubi-media computing and Workshops (Ubi-Media), 2017, Pattaya, Thailand, 1-8.

9. Al Kalbani J.; Bait Suwailam R.; Al Yafai A.; Al Abri D.; and Awadalla, M. (2015). Bus Detection System for Blind People using RFID. Proceedings of the 8th IEEE GCC Conference and Exhibition, Muscat, Oman, 16.

10. Regulatory status for using RFID in the EPC Gen 2 band ( 860 to $960 \mathrm{MHz}$ ) of the UHF spectrum. Retrieved June 13, 2017 from http://www.gs1.org/docs/epc/UHF_Regulations.pdf.

11. Barcodes Inc. (2015). QR Code Barcode Scanner - The Barcode Experts. Low Prices, Always. Retrieved May 20, 2017 from https://www.barcodesinc.com/cats/barcode-scanners/qr.htm.

12. Anusha, R.R.; and China, A.N. (2016). GPS and GSM Based School Children Tracking System. International Journal of Advanced Research in Computer Engineering and Technology, 5(6), 1704-1707.

13. Walmart, A. (2015). Garmin nuvi 52LM 5.0 GPS Bundle. Retrieved March 23, 2017, from http://www.walmart.com/ip/Garmin-nuvi-52LM-5.0-GPS-Bundle/39447962.

14. GPS.gov, (2014). GPS Accuracy. Retrieved May 20, 2017 from http://www.gps.gov/systems/gps/performance/accuracy/.

15. Brunnelli, M. (2015). Introduction to the Analytic Hierarchy Process. Springer.

16. Databases terminology and technology ICT (2010). Retrieved May 20, 2017 from http://www.teachct.com/gcse_new/databases/terminology/miniweb/pg3.htm.

17. Touch J., (1995). Report on MD5 Performance, RFC 1810. 